\title{
The reasoning criminal vs. Homer Simpson: conceptual challenges for crime science
}

\author{
Noémie Bouhana* \\ Department of Security and Crime Science, University College London, London, UK
}

Edited by:

Elena Rusconi, University College

London, UK

Reviewed by:

Elliot Berkman, University of Oregon,

USA

Nicola Lettieri, Isfol, Italy

*Correspondence:

Noémie Bouhana, Department of Security and Crime Science,

University College London, 35

Tavistock Square, WC1H 9EZ,

London, UK

e-mail:n.bouhana@ucl.ac.uk
A recent disciplinary offshoot of criminology, crime science (CS) defines itself as "the application of science to the control of crime." One of its stated ambitions is to act as a cross-disciplinary linchpin in the domain of crime reduction. Despite many practical successes, notably in the area of situational crime prevention (SCP), CS has yet to achieve a commensurate level of academic visibility. The case is made that the growth of CS is stifled by its reliance on a model of decision-making, the Rational Choice Perspective (RCP), which is inimical to the integration of knowledge and insights from the behavioral, cognitive and neurosciences (CBNs). Examples of salient developments in the CBNs are provided, as regards notably multiple-system perspectives of decision-making and approaches to person-environment interaction. Short and long-term benefits of integration for CS are briefly outlined.

Keywords: crime science, situational crime prevention, rational choice, decision-making, theory

\section{A VERY SHORT INTRODUCTION TO CRIME SCIENCE}

A recent disciplinary offshoot of criminology, crime science (CS) defines itself as "the application of science to the control of crime" (Laycock et al., 2005; Laycock, 2008:149). Problem-driven, CS is chiefly concerned with the design of social and technological systems in service to the needs of stakeholders and end-usersbe they industry, government, security agencies, or the general public. Underpinning CS and its preferred approach to crime reduction, situational crime prevention (SCP), is the premise that crime is best tackled by targeting its immediate causes. This focus on proximate factors is intentionally lopsided. While the necessary conditions of crime are defined as the intersection in time and space of a motivated offender and a suitable target in the absence of a capable guardian, relatively little attention has been paid to the "offender" part of the equation. CS digs its philosophical roots in the 18th Century Classical School, whereby Man is understood as an essentially self-interested animal driven by desires which he seeks to fulfill while incurring the least amount of effort. Susceptibility to temptation is thus taken as a given and CS looks to situational control-the removal of temptations—as the most promising crime reduction strategy. "Opportunity makes the thief": remove the opportunity, increase the effort and reduce the rewards of offending, and the crime will be prevented (Clarke, 2012).

The effectiveness of this approach has been demonstrated against a diverse range of crime problems. The promise of technological solutions and an emphasis on practical problem-solving have been popular with law enforcement agencies, and the claim was made that CS would soon eclipse criminology departments within universities (Clarke, 2004). However, CS has yet to achieve commensurate visibility in the academic sphere. This paper contends that the conceptual limitations of CS's standard model of decision-making, the Rational Choice Perspective (RCP), as well as the discipline's largely "bottom-up" research programme, hold it back from fulfilling its stated ambition to act as a cross-disciplinary linchpin (Laycock et al., 2005). The case is made that CS must look to developments in the cognitive, behavioral and neurosciences (henceforth, Cognitive and Neurosciences $(\mathrm{CBNs}))$ to address RCP's shortcomings. Examples of developments which suggest potential for integration are provided. In conclusion, the benefits of integration are further outlined.

\section{THE CASE FOR "BOUNDED" PARSIMONY}

It is not possible to leave the offender out of crime prevention altogether. In order to "increase effort" and "reduce rewards", a model of criminal decision-making is needed. For this purpose, the fathers of SCP adopted the RCP (Clarke et al., 1985; Cornish et al., 2008). As presented, RCP is not a theory per se, but a heuristic device, a "good enough" conceptual model which provides a schematic understanding of how offenders make decisions - evaluating, to the best of their abilities, the costs and benefits of their actions. Armed with this basic understanding, the crime controller can design an array of situational techniques to influence the offender's decisional process away from crime (Smith and Clarke, 2012).

While RCP has met with notable success as an engineering heuristic, it has fallen short as a model of offender decisionmaking (Wortley et al., 2013). Although the framework acknowledges, on the one hand, the less-than-rational aspects of offender decision-making - criminal rationality is described as "bounded"-it implies, on the other, that the problem isn't worth agonizing over: a parsimonious, as-if model, unencumbered 
by the vagaries of human affect and cognition, should serve the crime controllers well enough (Smith and Clarke, 2012). As Wortley et al. (2013) observes, this state of affairs has had the consequence of stifling theoretical development in CS, so much so that RCP has remained essentially static since the 1980s. One may take Wortley's critique further and observe that other theoretical perspectives within the "family" of opportunity theories-notably, the Routine Activity Approach (Cohen and Felson, 1979)—have likewise remained relatively untouched. Opportunity theories are still, to a large extent, axiomatic statements rather than explanations of the causal processes which bring crime about (Wikström et al., 2011). This is illustrated by the oft-repeated claim that opportunities cause crime (Felson and Clarke, 1998); for it is not, of course, the opportunity which causes the crime, but its perception by the offender (the Thomas Theorem in action), among other processes: opportunities, whether provocations or temptations, are not criminal in themselves. To address this problem, some have proposed that the ecological concept of affordance (Gibson, 1979) should replace opportunity in CS parlance (Pease et al., 2006). However, affordance has yet to be integrated into the wider opportunity control framework. To take affordance on board, a model of criminal action is required which explains motivation in terms of the interaction between individual and situation, instead of postulating it as a given.

The move towards a more dynamic, interactionist model has been resisted, for fear that it would compromise RCP's radical parsimony, a condition of its heuristic usefulness. Faced with evidence of the non-rational features of offender decision-making, the strategy has been to stretch the concept of "rationality" to encompass the new phenomena. Drives to criminal action are restated as factors in a cost-benefit analysis. Psychological rewards (e.g., excitement), moral emotions (e.g., guilt, shame), social inducements (e.g., status), psychobiological factors (e.g., addiction), and so on, are reinterpreted in "rational" terms (e.g., Clarke et al., 1997). This approach renders the model impregnable, but runs roughshod over Einstein's admonition that theory should "make the irreducible basic elements as simple and as few as possible without having to surrender the adequate representation of a single datum of experience" (Einstein, 1934:165, emphasis added). The construct which explains everything explains nothing: the more phenomena is stuffed into the construct, the emptier it becomes. "Bounded" rather than radical parsimony would seem the more reasonable option.

\section{DRAWBACKS OF "BOTTOM-UP" RESEARCH}

Calls to overhaul RCP and bring the offender back into SCP have been sounded in the past (Ekblom and Tilley, 2000; Wortley, 2001; Wortley et al., 2013), but have fallen on reluctant ears. New SCP techniques concerned with situational precipitators have been added to the catalogue (Cornish et al., 2003), falling far short of a conceptual shake-up. CS's continuing identity struggle may explain this inertia: "science" moniker aside, CS is fundamentally an engineering discipline, with a self-confessed preference for short-term problem-solving (Laycock et al., 2005). At the outset, SCP was established as the technological framework most likely to deliver returns. A number of technological rules and design principles, most of them implicated in opportunity control, were identified, which produced reliable results. The discipline's scientific programme was thus largely circumscribed to those research activities which provided a knowledge-base for the design of opportunity control technologies (broadly defined), or contributed to the testing, validation and refinement of those technological rules and design principles at the heart of the discipline.

Arguably, the crime scientist's trademark question is, "So what?" (Laycock, 2012). If the topic is not self-evidently useful to crime control, it is not worth investigating. On the upside, this instrumental approach, whereby CS's engineering ambitions dictate the discipline's research activity, has produced reliable analytical tools and prevention technologies, which have achieved concrete gains in terms of crime reduction. On the downside, this relatively narrow research agenda has done little to encourage inquiry driven by "big questions". Indeed, crime scientists have been known to take criminologists to task for studying the "wrong" kinds of causes and failing to be more problem-oriented (Clarke, 2004), as if only a finite number of scientific questions about crime were worth asking.

The concern is that this "bottom-up" research agenda has insularised CS from a wealth of knowledge in other disciplines, notably the CBNs, as much as it has impeded theoretical growth from within. Yet a field which looks to medicine as a desirable model of cross-disciplinarity (Laycock et al., 2005) needs a conceptual framework which affords (in Gibson's sense of the word) disciplinary integration. Medicine and its parent disciplines share the foundations of a systemic (chemical, biological, psychosocial, ecological, and so on) understanding of the human organism and its environment. To achieve its stated goal, CS needs, if not a unified framework, then conceptual models which are not inimical to neighboring research programmes. As a first step, opportunity perspectives should clarify what they mean by "bounded rationality" and formulate explicit mechanisms of person-situation interaction (which will also necessitate a clear definition of "situation"; Snyder, 2013). Examples of developments in the CBNs may illustrate the value of integration.

\section{ENTERS HOMER SIMPSON, STAGE RIGHT}

The outsider looks on with envy at the effervescence which has characterized the growth and, increasingly, the integration of the CBNs in recent years. Given the breakneck speed of research in these domains, an overview isn't attempted, but it is noteworthy that the surge of activity has often been accompanied, if not triggered, by an empirical challenge to single-factor (notably rationalist) models and theories.

In social psychology, dual-process models (Evans, 2003; Mischel et al., 2004; Kahneman et al., 2005; Kahneman, 2011) followed from observations that departures from classical rationality are an ubiquitous feature of human thinking (Kahneman et al., 1982; Kahneman, 2011). In moral psychology, dual models of moral judgment have likewise emerged which call into question the Kholbergian view of moral development, adopting instead an adaptationist perspective in which moral 
intuitions underpin moral judgment as much as moral reasoning, if not more so (Haidt, 2001; Greene and Gazzaniga, 2009; Cushman et al., 2010).

Of particular interest, given SCP's original borrowing of the rational perspective from economics, has been the development of behavioral economics, which built upon social psychology's insights to address commonly observed violations of the standard neo-classic model (Thaler, 1991; Mullainathan et al., 2001). As Camerer et al. (2004) put it, "At the core of behavioral economics is the conviction that increasing the realism of the psychological underpinnings of economic analysis will improve economics on its own terms-generating theoretical insights, making better predictions of field phenomena, and suggesting better policy." The scientific gain, behavioral economists feel, is worth renouncing the seductive (i.e., simple and clear-cut), but ultimately misleading, solutions proposed by standard models. While neo-classical economics would like people to think like Mr. Spock, the average human being is rather closer to Homer Simpson (Thaler and Sunstein, 2008). Policies aimed at improving anything from individual health to personal finances, road safety, energy savings, and so on, are better designed while keeping Springfield's most famous resident in mind. Boosted by these developments in behavioral economics, neuroeconomics has set out to open the "black box" of the economic brain (Camerer et al., 2005), progressively adding detail to an "emorational" organ (Oullier et al., 2010) constituted of neural systems so enmeshed it makes little sense to study decision-making without reference to emotional states (Sanfey et al., 2006), or-another fundamental revision to the standard models - without reference to the socio-physical environment.

\section{THE FUTURE'S BRIGHT, THE FUTURE'S INTERACTIVE}

The emphasis on system interaction within the organism has been accompanied by growing attention to organismenvironment interaction. Given the importance of self-control to the explanation of criminal behavior (Tooby and Cosmides, 2007), research on self-regulation is particularly instructive, revealing self-control to be less of a fixed "trait" than a complex situational mechanism. How much of this resource individuals may draw on in any given circumstance is influenced by situational features, as well as individual factors. Self-control can be depleted by the prior exercise of self-control (Baumeister et al., 2007) and by the exercise of choice between alternatives (Vohs et al., 2008), with implications for the subsequent ability to self-monitor, cope with stress, control aggression, think logically, and so on. It can be depleted vicariously by watching others exercise restraint (Ackerman et al., 2009), but can also be restored vicariously by taking on the perspective of others engaged in self-control replenishing activities (Egan et al., 2012). Relevantly, self-regulatory depletion is associated with unethical behavior in well-intentioned individuals, though much less so in individuals with highly internalized moral standards, plausibly because they do not need to engage in higher cognitive processes, but automatically disregard the opportunity to behave unethically (Gino et al., 2011). This observation would seem to support situational action models of moral rule-breaking (Svensson et al., 2010).
More generally, self-regulation is sensitive to cognitive load. Decisions-making in environments which impose a high cognitive burden on individuals can lead to greater reliance on (more economical) automated decision-making, which in turn can lead to cognitive shortcuts, such as racial stereotyping (Burgess, 2010). Research into the causes of self-defeating decision-making among the poor suggests that the very conditions that define poverty, such as scarcity, impact decision-making through biosocial mechanisms which produce attentional shifts, self-control depletion, and reduce cognitive capacity generally (Spears, 2010; Shah et al., 2012; Mani et al., 2013). Self-regulation depletion also appears affected by self-belief, whereby individuals' implicit theories of willpower moderate self-control depletion (Job et al., 2010). Overall, modern research offers an increasingly sophisticated picture of self-control as a fluctuating resource subject to the interaction of an array of individual and socio-contextual factors (see Inzlicht and Schmeichel, 2012). It also suggests avenues to integrate mechanistically so-called "root causes" (e.g., poverty) and situational choice perspectives, traditionally at odds in the context of crime studies.

Interaction is, naturally, a chief concern of those disciplines working within an adaptationist framework. In the context of evolutionary psychology, "rationality" is not portrayed as a universal construct; rather, processes are understood as domain-specific and may produce "faulty" choices when considered from another behavioral domain's point-of-view. In this sense, rationality is not so much bounded as ecological (Tooby and Cosmides, 2007). This perspective suggests a framework for the continued development of still-rare ecological studies of criminal decision-making (Snook et al., 2011). It might be worthwhile in that context to explore how domain-specific processes relate (or not) to domain-general processes (Chiappe and MacDonald, 2005), as well as to niche construction (Laland and Brown, 2006).

Beyond functional explanations, evolutionary perspectives of human development have yielded constructs such as "differential susceptibility to the environment" and "biological sensitivity to context", which add to an understanding of the role of individual differences in the outcome of person-environment interactions (Ellis et al., 2011). They suggest that heightened vulnerability to context runs both ways-some individuals are more susceptible to both negative and positive influences_-and raise intriguing questions as to the persistent effect, if any, of this susceptibility into adulthood. Even these exceedingly brief examples suggest significant potential to progress CS's take on person-situation interaction beyond its (relatively) primitive state.

\section{SO WHAT?}

The preceding should not be taken as an entreaty for crime scientists to give up their preferred methods and reach for the fMRI-though, as with previous successful imports from epidemiology (e.g., Bowers and Johnson, 2004), greater integration will likely result in substantial methodological gains. Nor is it a demand to adopt any given approach wholesale. Indeed, the most onerous part of the conceptual shift advocated here will be to keep up with fundamental debates internal to other disciplines (e.g., Bolhuis et al., 2011). It should, however, be taken as a plea for scientific realism, for the development of 
theories of human behavior which go beyond axiomatic, "as-if" theoretical frameworks to specify the constellation of biosocial mechanisms which account for the phenomenon (Bunge et al., 2006). As it stands, CS's standard model, RCP, isolates it from a wealth of knowledge in contemporary disciplines. This is a major obstacle to the development of a modern science of crime prevention.

This proposal for a more modern approach to conceptual development should not be interpreted, either, as a request to relinquish the problem-solving side of the business. Tackling practical problems generates hypotheses and throws up invaluable challenges to theoretical assumptions. Furthermore, embracing the CBN knowledge-base is bound to open up short-term avenues for crime prevention engineering. Research on the deleterious effects of cognitive load on healthcare decision-making already suggests that environmental changes, learned routines and "reflective practice" could improve the performance of crime controllers working in stressful settings (Burgess, 2010). Understanding the rewards associated with automated brain processes hints at strategies to tackle resistance to change in law enforcement organizations (Becker and Cropanzano, 2010). Experiments which elicit moral emotions such as disgust, combined with eye-tracking studies of anti-smoking warnings, could inform the design and evaluation of crime prevention publicity campaigns (see Oullier and Sauneron, 2010). Likewise, neuroimaging studies of the Ultimatum Game-which investigate why participants "irrationally" turn down money when faced with offers perceived as unfairmight help crime controllers understand why "rational" crime prevention advice is sometimes spiritedly rejected by potential victims (such as advice which suggests women should alter their behavior to prevent sexual assault).

More ambitiously, the convergence of cognitive neuroscience, social psychology, architecture (e.g., Sternberg and Wilson,

\section{REFERENCES}

Ackerman, J. M., Goldstein, N. J., Shapiro, J. R., and Bargh, J. A. (2009). You wear me out: the vicarious depletion of self-control. Psychol. Sci. 20, 326-332. doi: 10.1111/j. 1467-9280.2009.02290.x

Baumeister, R. F., Vohs, K. D., and Tice, D. M. (2007). The strength model of self-control. Curr. Dir. Psychol. Sci. 16, 351-355. doi: 10.1111/j. 1467-8721.2007.00534.x

Becker, W. J., and Cropanzano, R. (2010). Organizational neuroscience: the promise and prospects of an emerging discipline. J. Organ. Behav. 31, 1055-1059. doi: 10.1002/job. 668

Bolhuis, J. J., Brown, G. R., Richardson, R. C., and Laland, K. N. (2011). Darwin in mind: new opportunities for evolutionary psychology. PLoS Biol. 9:e1001109. doi: 10.1371/journal. pbio. 1001109

2006), consumer studies (e.g., Mick et al., 2004), and crime prevention might inspire interdisciplinary research into the design of "neurocognitively sustainable" environments, which would aim to minimize deleterious interaction (in terms of cognitive overload, depletion of self-control, and so on), with the prospect of benefit diffusion across multiple categories of social problems. The perspective of a wide-ranging contribution from evolutionary psychology has already captured the imagination of crime scientists (Roach and Pease, 2013), though reminders that adaption is an onerous explanatory concept, and that accounts of ultimate (evolutionary) causes must be accompanied by an understanding of proximal (e.g., neuropsychological) mechanisms, should be heeded (de Waal, 2002). In criminology, embryonic comparative research into the executive functioning of white collar criminals (Raine et al., 2012) hints at the possibility of tailoring prevention technologies by offending type. Executive functioning-self-regulation, but also the functions which underpin cognitive adaptability and flexibilityis likely to be a fruitful area of research for CS should it seek to account more deeply for the failure of many criminals to displace. When explaining human behavior, evaluating causal factors in isolation makes poor sense. A science of crime prevention should become comfortable with multilevel theorizing.

This paper proceeded from a simple premise: that a scientific discipline which aims to capture the imagination of future generations of researchers cannot exist only to solve practical problems; it must also set out to answer fundamental questions. While technology must be simple enough for end-users to implement, the science which is the bedrock of these technologies should be as complex as it needs to be. "Good enough" theory surrenders too much of experience to be worth the short-term benefits to any scientific discipline.

and M. Rabin (New York: Princeton University Press), 3-51.

Camerer, C., Loewenstein, G., and Prelec, D. (2005). Neuroeconomics: how neuroscience can inform economics. J. Econ. Lit. 43, 9-64. doi: 10.1257/0022051053737843

Chiappe, D., and MacDonald, K. (2005). The evolution of domaingeneral mechanisms in intelligence and learning. J. Gen. Psychol. 132, 5-40. doi: 10.3200/GENP.132.1. 5-40

Clarke, R. V. (2004). Technology, criminology and crime science. Eur. J. Crim. Policy Res. 10, 55-63. doi: 10.1023/B:CRIM.0000037557. 42894.f7

Clarke, R. V. (2012). Opportunity makes the thief. Really? And so what? Crime Sci. 1:3. doi: 10. 1186/2193-7680-1-3

Clarke, R. V., and Cornish, D. B. (1985). "Modeling offenders' decisions: a framework for research and policy," in Crime and Justice: An Annual Review of Research Vol. 6, eds M. Tonry and N. Morris (Chicago: University of Chicago Press), 147-185.

Clarke, R. V., and Homel, R. (1997). "A revised classification of situational crime prevention techniques," in Crime Prevention at the Crossroads, ed S. P. Lab (Cincinnati, OH: Anderson), 17-30.

Cohen, L. E., and Felson, M. (1979). Social change and crime rate trends: a routine activities approach. Am. Sociol. Rev. 44, 588-608. doi: 10. 2307/2094589

Cornish, D. B., and Clarke, R. V. (2003). "Opportunities, precipitators and criminal decisions: a reply to Wortley's critique of situational crime prevention," in Theory for Practice in Situational Crime Prevention, eds M. Smith and D. B. Cornish (Monsey, NY: Criminal Justice Press), 41-96. 
Cornish, D. B., and Clarke, R. V. (2008). "The rational choice perspective," in Environmental Criminology and Crime Analysis, eds R. Wortley and L. Mazerolle (Cullompton: Willan), 21-47.

Cushman, F., Young, L., and Greene, J. D. (2010). "Our multi-system moral psychology: towards a consensus view," in The Oxford Handbook of Moral Psychology, eds J. Doris, G. Harman, S. Nichols, J. Prinz, W. Sinnott-Armstrong and S. Stich (New York: Oxford University Press), 47-71.

de Waal, F. (2002). Evolutionary psychology: the wheat and the chaff. Curr. Dir. Psychol. Sci. 11, 187-191. doi: 10.1111/1467-8721. 00197

Egan, P., Hirt, E., and Karpen, S. (2012). Taking a fresh perspective: vicarious restoration as a means of recovering self-control. J. Exp. Soc. Psychol. 48, 457-465. doi: 10.1016/j. jesp.2011.10.019

Einstein, A. (1934). On the method of theoretical physics. Philos. Sci. 1, 163-169. doi: 10.1086/286316

Ekblom, P., and Tilley, N. (2000). Going equipped: criminology, situational crime prevention and the resourceful offender. Br. J. Criminol. 40, 376-398. doi: 10.1093/bjc/40.3. 376

Ellis, B. J., Boyce, W. T., Belsky, J., Bakermans-Kranenburg, M. J., and Van Ijzendoorn, M. H. (2011). Differential susceptibility to the environment: an evolutionaryneurodevelopmental theory. Dev. Psychopathol. 23, 7-28. doi: 10. 1017/S0954579410000611

Evans, J. S. (2003). In two minds: dual-process accounts of reasoning. Trends Cogn. Sci. 7, 454-459. doi: 10. 1016/j.tics.2003.08.012

Felson, M., and Clarke, R. V. (1998). Opportunity Makes the Thief: Practical Theory for Crime Prevention. Police Research Series, Paper 98. London: Home Office.

Gibson, J. J. (1979). The Ecological Approach to Perception. Hillsdale, NJ: Lawrence Erlbaum Associates.

Gino, F., Schweitzer, M., Mead, N., and Ariely, D. (2011). Unable to resist temptation: how selfcontrol depletion promotes unethical behavior. Organ. Behav. Hum. Decis. Process 115, 191-203. doi: 10.1016/j.obhdp. 2011.03.001

Greene, J. D. (2009). "The cognitive neuroscience of moral judgment," in The Cognitive Neurosciences, 4th Edn. ed M. S. Gazzaniga (Cambridge, MA: MIT Press), 987-1002.
Haidt, J. (2001). The emotional dog and its rational tail: a social intuitionist approach to moral judgment. Psychol. Rev. 108, 814-834. doi: 10. 1037//0033-295x.108.4.814

Inzlicht, M., and Schmeichel, B. J. (2012). What is ego depletion? Toward a mechanistic revision of the resource model of self-control. Perspect. Psychol. Sci. 7, 450-463. doi: $10.1177 / 1745691612454134$

Job, V., Dweck, C. S., and Walton, G. M. (2010). Ego depletion-is it all in your head? implicit theories about willpower affect self-regulation. Psychol. Sci. 21, 1686-1693. doi: 10. 1177/0956797610384745

Kahneman, D. (2011). Thinking Fast and Slow. New York: Farrar, Straus and Giroux.

Kahneman, D., and Frederick, S. (2005). "A model of heuristic judgment," in The Cambridge Handbook of Thinking and Reasoning, eds K. J. Holyoak and R. G. Morrison (New York: Cambridge University Press), 267-293.

Kahneman, D., Slovic, P., and Tversky, A. (eds.) (1982). Judgement Under Uncertainty: Heuristics and Biases. Cambridge: Cambridge University Press.

Laland, K. N., and Brown, G. R. (2006). Niche construction, human behaviour and the adaptivelag hypothesis. Evol. Anthropol. 15, 95-104. doi: 10.1002/evan. 20093

Laycock, G. (2005). "Defining crime science," in Crime Science: New Approaches to Preventing and Detecting Crime, eds M. J. Smith and N. Tilley (Cullompton: Willan), 3-25.

Laycock, G. (2008). Introduction: special edition on crime science. Policing 2, 149-153. doi: 10. 1093/police/pan028

Laycock, G. (2012). Editorial introduction to 'Opportunity makes the thief. Really? And so what?'. Crime Sci. 1:2. doi: 10.1186/2193-7680-1-2

Mani, A., Mullainathan, S., Shafir, E., and Zhao, J. (2013). Poverty impedes cognitive function. Science 341, 976-980. doi: 10.1126/science. 1238041

Mick, D. G., Broniarczyk, S. M., and Haidt, J. (2004). Choose, choose, choose, choose, choose, choose, choose: emerging and prospective research on the deleterious effects of living in consumer hyperchoice. J. Bus. Ethics 52, 207-211. doi: $10.1023 /$ B:BUSI.0000035906. 74034.d4

Mischel, W., and Ayduk, O. (2004). "Willpower in a cognitive-affective processing system: the dynamics of delay of gratification," in Handbook of Self-Regulation: Research, Theory, and Applications, eds R. F. Baumeister and K. D. Vohs (New York: Guilford), 99-129.

Mullainathan, S., and Thaler, R. H. (2001). "Behavioral economics," in International Encyclopedia of the Social and Behavioral Sciences, eds N. Smelser and P. Bates (New York: Pergamon), 1094-1110.

Oullier, O. (2010). "The useful brain: why neuroeconomics might change our views on rationality and a couple of other things," in The Irrational Economist: Making Decisions in a Dangerous World, eds E. MichelKerjan and P. Slovic (New York: Public Affairs), 88-96.

Oullier, O., and Sauneron, S. (eds.) (2010). Improving Public Health Prevention with Behavioural, Cognitive and Neuroscience. Paris: La Documentation Française.

Pease, K. (2005). "Science in the service of crime reduction," in Handbook of Crime Prevention and Community Safety, ed N. Tilley (Cullumpton: Willan Press), 171-197.

Pease, K. (2006). "No through road: closing pathways to crime," in Crime Reduction and the Law, eds K. Moss and M. Stephens (London: Routledge), 50-66.

Raine, A., Laufer, W. S., Yang, Y., Narr, K. L., Thompson, P., and Toga, A. W. (2012). Increased executive functioning, attention, and cortical thickness in white-collar criminals. Hum. Brain Mapp. 33, 2932-2940. doi: $10.1002 / \mathrm{hbm} .21415$

Roach, J., and Pease, K. (2013). Evolution and Crime. London: Routledge.

Sanfey, A. G., Loewenstein, G., McClure, S. M., and Cohen, J. D. (2006). Neuroeconomics: crosscurrents in research on decisionmaking. Trends Cogn. Sci. 10, 108 116. doi: 10.1016/j.tics.2006.01 009

Shah, A. K., Mullainathan, S., and Shafir, E. (2012). Some consequences of having too little. Science 338, 682-685. doi: 10.1126/science. 1222426

Smith, M. J., and Clarke, R. V. (2012). "Situational crime prevention: classifying techniques using 'good enough' theory," in The Oxford Handbook of Crime Prevention, eds B. C. Welsh and D. P. Farrington (New York: Oxford University Press), 291-315.

Snook, B., Dhami, M. K., and Kavanagh, J. M. (2011). Simply criminal: predicting burglars' occupancy decisions with a simple heuristic. Law Hum. Behav. 35,
316-326. doi: 10.1007/s10979-0109238-0

Snyder, M. (2013). B = f (P, S): perspectives on persons and situations, from Lewin to Bond and beyond. Asian J. Soc. Psychol. 16, 16-18. doi: 10.1111/ajsp.12013

Spears, D. (2010). Economic Decisionmaking in Poverty Depletes Behavioral Control (Working Paper No. 213). Princeton: Center for Economic Policy Studies. Retrieved from http://www.princeton.edu/ ceps/workingpapers/213spears.pdf.

Sternberg, E. M., and Wilson, M. A. (2006). Neuroscience and architecture: seeking common ground. Cell 127, 239-242. doi: 10.1016/j.cell. 2006.10.012

Svensson, R., Pauwels, L., Weerman, F. (2010). Does the effect of self-control on adolescent offending vary by level of morality? Crim. Justice Behav. 37, 732-743. doi: $10.1177 / 0093854810366542$

Thaler, R. H. (1991). The Winner's Curse: Paradoxes and Anomalies of Economic Life. Princeton: Princeton University Press.

Thaler, R. H., and Sunstein, C. (2008). Nudge: Improving Decisions About Health, Wealth and Happiness. London: Penguin

Tooby, J., and Cosmides, L. (2007). Evolutionary psychology, ecological rationality, and the unification of the behavioral sciences. Behav. Brain Sci. 30, 42-43. doi: 10. 1017/s0140525x07000854

Vohs, K. D., Baumeister, R. F., Schmeichel, B. J., Twenge, J. M., Nelson, N. M., and Tice, D. M. (2008). Making choices impairs subsequent self-control: a limited resource account of decision making, selfregulation, and active initiative. J. Pers. Soc. Psychol. 94, 883-898. doi: 10.1037/0022-3514.94.5.883

Wikström, P.-O. (2011). "Does everything matter? Addressing the problem of causation and explanation in the study of crime," in When Crime Appears: The Role of Emergence, eds J. M. McGloin, C. J. Sullivan and L. W. Kennedy (London: Routledge), 53-72.

Wikström, P.-O., and Trieber, K. (2007). The role of self-control in crime causation: beyond Gottfredson and Hirschi's general theory of crime. Eur. J. Criminol. 4, 237-264. doi: 10.1177/14773708070 74858

Wortley, R. (2001). A classification of techniques for controlling situational precipitators of crime. Secur. J. 14, 63-82. doi: 10.1057/palgrave sj. 8340098 
Wortley, R. (2013). "Rational choice and offender decision making: lessons from the cognitive sciences," in Cognition and Crime: Offender Decision Making and Script Analysis, eds B. Leclerc and R. Wortley (London: Routledge), 237-251.

Conflict of Interest Statement: The authors declare that the research was conducted in the absence of any commercial or financial relationships that could be construed as a potential conflict of interest.

Received: 18 August 2013; accepted: 28 September 2013; published online: 23 October 2013.

Citation: Bouhana N (2013) The reasoning criminal vs. Homer Simpson: conceptual challenges for crime science. Front. Hum. Neurosci. 7:682. doi: 10.3389/fnhum.2013.00682

This article was submitted to the journal Frontiers in Human Neuroscience.

Copyright (c) 2013 Bouhana. This is an open-access article distributed under the terms of the Creative Commons Attribution License (CC BY).
The use, distribution or reproduction in other forums is permitted, provided the original author(s) or licensor are credited and that the original publication in this journal is cited, in accordance with accepted academic practice. No use, distribution or reproduction is permitted which does not comply with these terms. 